\title{
Accidental self-injection of intravenous epinephrine by healthcare personnel
}

\author{
Hyunseung Koh ${ }^{1}$, Duk Ho Kim ${ }^{1}$, Jinseong Kim ${ }^{1}$, Heebum Yang ${ }^{1, *}$
}

\author{
${ }^{1}$ Department of Emergency Medicine, \\ Nowon Eulji Medical Center, Eulji \\ University, Seoul, Republic of Korea \\ *Correspondence \\ heebeom@gmail.com \\ (Heebum Yang)
}

\begin{abstract}
Epinephrine is a key drug used in resuscitation, including advanced life support situations. A 28-year-old nurse inadvertently injected herself with an ampule of epinephrine and was brought to the emergency department. The injection caused a drop in blood pressure, pulmonary edema, and cardiac enzyme elevation. Upon further evaluation, echocardiography revealed left ventricular wall motion abnormality with reduced ejection fraction. The patient was diagnosed with stress-induced cardiomyopathy (SCMP) and was treated appropriately. After a short stay in the intensive care unit as the vital signs were affected, the patient was transferred to the ward on the second day of hospitalization and was well enough to be discharged on the fifth day. The treatment of SCMP induced by epinephrine is largely conservative with a symptomatic approach. In most cases, the outcome is favorable. Inappropriate drug use, accidental or otherwise, can pose a great risk. More stringent caution should be practiced by medical staff in handling medication to prevent serious medication-related accidents.
\end{abstract}

\section{Keywords}

Epinephrine; Overdose; Health personnel; Self-administration

\section{Introduction}

Among its many beneficial uses, epinephrine is an integral part of treatment for life-threatening situations such as cardiac arrest and anaphylaxis. However, if the drug is not properly administered in the recommended dose and advised route, serious complications may occur in the patient [1]. Herein, we report a case of accidental self-injection of intravenous epinephrine by a nurse and its causative effects.

\section{Case presentation}

A 28-year-old surgical nurse was transferred from another hospital due to shock after accidental intravenous selfadministration of epinephrine. According to the information received, she was mildly drowsy with a systolic blood pressure in the $70 \mathrm{~s}$ even after infusion of $1.5 \mathrm{~L}$ isotonic saline. After $3 \mathrm{~h}$ of observation, the transferring physician decided to send the patient to our emergency department.

Upon the patient's arrival, focused history taking and physical examination were conducted. The patient stated that she had severe menstrual cramps while preparing for the surgery as a scrub nurse. Rather than changing her shift with another nurse, due to the circumstances, she chose to self-administer an analgesic and work. However, she accidentally injected one ampule of $1 \mathrm{mg} / \mathrm{mL}$ ( 1 : 1000 solution) epinephrine intravenously instead of one ampule of $30 \mathrm{mg} / \mathrm{mL}$ ketorolac tromethamine since these two ampules had a similar colored label. Her initial vital signs were as follows: blood pressure, $82 / 61 \mathrm{mmHg}$; heart rate, 80 beats per minute; respiratory rate, 19 breaths per minute; body temperature, $36.3{ }^{\circ} \mathrm{C}$; percutaneous oxygen saturation, $86 \%$. Bedside electrocardiography did not reveal tachycardia or other significant abnormalities (Fig. 1). The patient's treatment began under the initial impression of rebound hypotension following epinephrine injection. Two liters of oxygen was administered nasally to improve her oxygen saturation, and an additional $400 \mathrm{~mL}$ isotonic solution was administered. Chest radiography revealed pulmonary edema, although the patient had no known history of lung disease (Fig. 2A). An arterial line and central line were inserted for continuous vital sign monitoring. The central venous pressure was $26.5 \mathrm{cmH}_{2} \mathrm{O}$, and her troponin-I level was elevated. The level of creatine kinase-MB was $3.3 \mathrm{ng} / \mathrm{mL}$ (normal [N]: 1-4.3 $\mathrm{ng} / \mathrm{mL}$ ), troponin-I was $0.69 \mathrm{ng} / \mathrm{mL}(\mathrm{N}: 0.01-0.02 \mathrm{ng} / \mathrm{mL})$, and B-type natriuretic peptide was $38.7 \mathrm{ng} / \mathrm{mL}(\mathrm{N}: 0-100 \mathrm{ng} / \mathrm{mL}$ ). Brain computed tomography did not reveal any significant abnormalities that might explain the patient's mental status. An initial norepinephrine dose of $2 \mu \mathrm{g} / \mathrm{min}$ was administered to elevate her blood pressure. A Foley catheter was inserted, and one ampule of furosemide $(20 \mathrm{mg} / 2 \mathrm{mg})$ was administered intravenously for the management of pulmonary edema and presumed congestive heart failure. Echocardiography revealed normal-sized cardiac chambers with reduced left ventricular systolic function (ejection fraction 45\%) and regional wall motion abnormality suggestive of stress-induced cardiomyopathy (SCMP) (Fig. 3). 


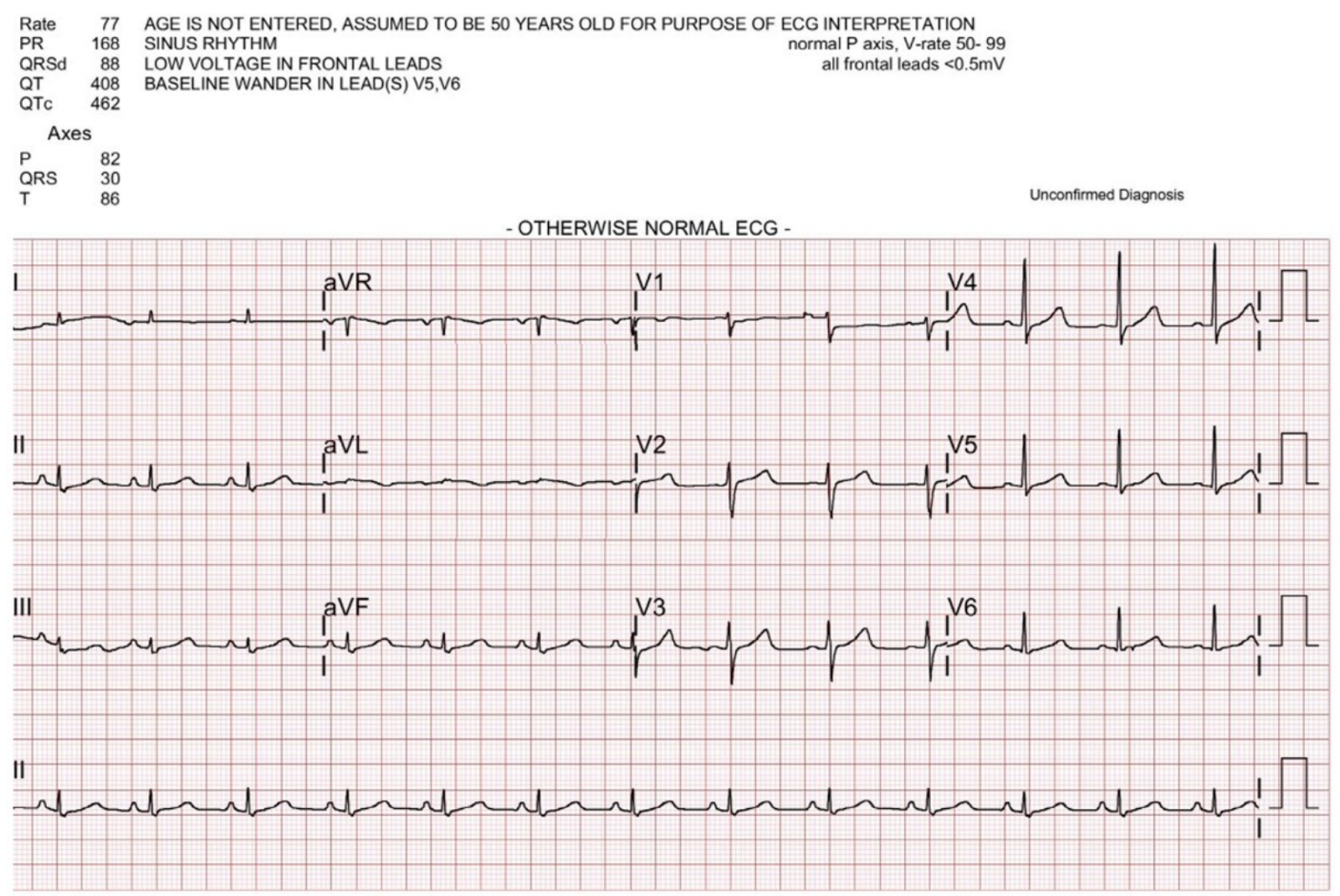

F I G U R E 1. Initial electrocardiogram (ECG) in the emergency department (ED) was normal sinus rhythm (3 hours after epinephrine injection).
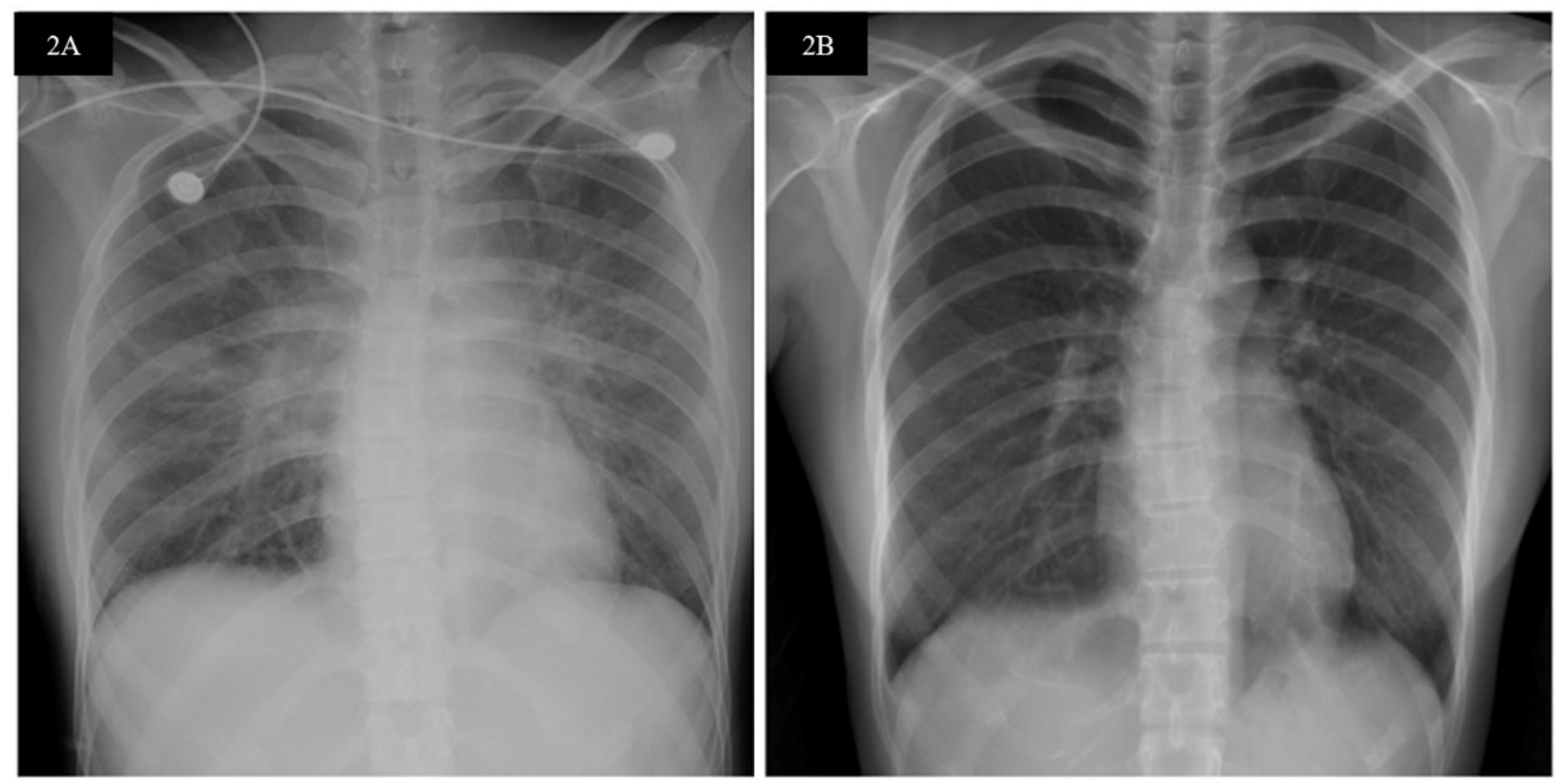

F I G U R E 2. (A) Significant lung exudation and edema in chest X-ray (day 1), (B) Improving pulmonary edema (day 3).

The patient was admitted to the intensive care unit (ICU) after initial evaluation and management in our emergency department. The dose of norepinephrine was increased to 5 $\mu \mathrm{g} / \mathrm{min}$ in the ICU to maintain a mean arterial pressure of over $60 \mathrm{mmHg}$. The patient's dyspnea did not improve; therefore, high-flow oxygen of $40 \mathrm{~L} / \mathrm{min}$ with a fraction of inspired oxygen of 0.5 was administered to the patient. Furosemide was administered intravenously to improve lung exudation and pulmonary edema. The patient's vital signs and symptoms gradually improved on the second day in the ICU. On the second day of hospitalization, norepinephrine was tapered down to $0.5 \mu \mathrm{g} / \mathrm{min}$ and then stopped without any further drop in the patient's blood pressure. The blood pressure remained above $100 / 60 \mathrm{mmHg}$. She was transferred to the general ward on the second day of hospitalization. The supplemental oxygen supply was slowly reduced until it was no longer required 


\section{Parasternal short axis - base}

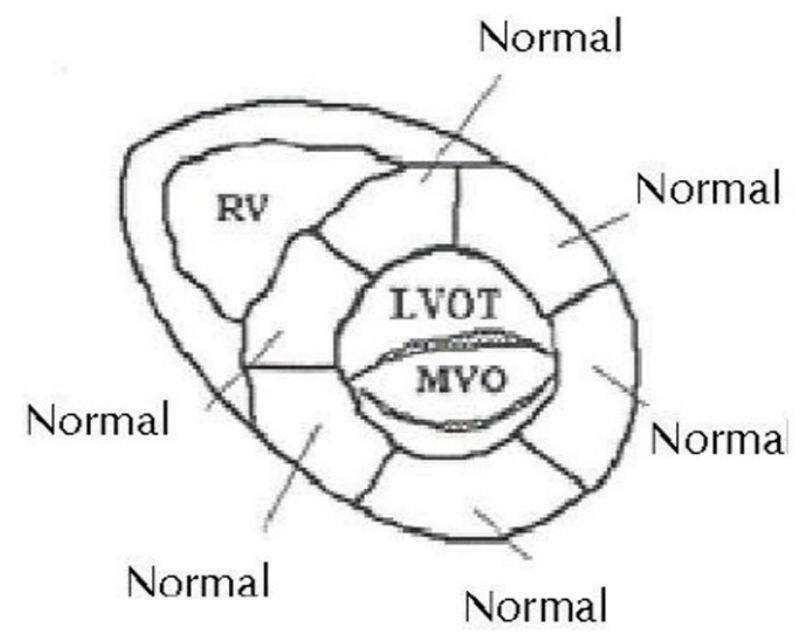

\section{Parasternal short axis - mid}

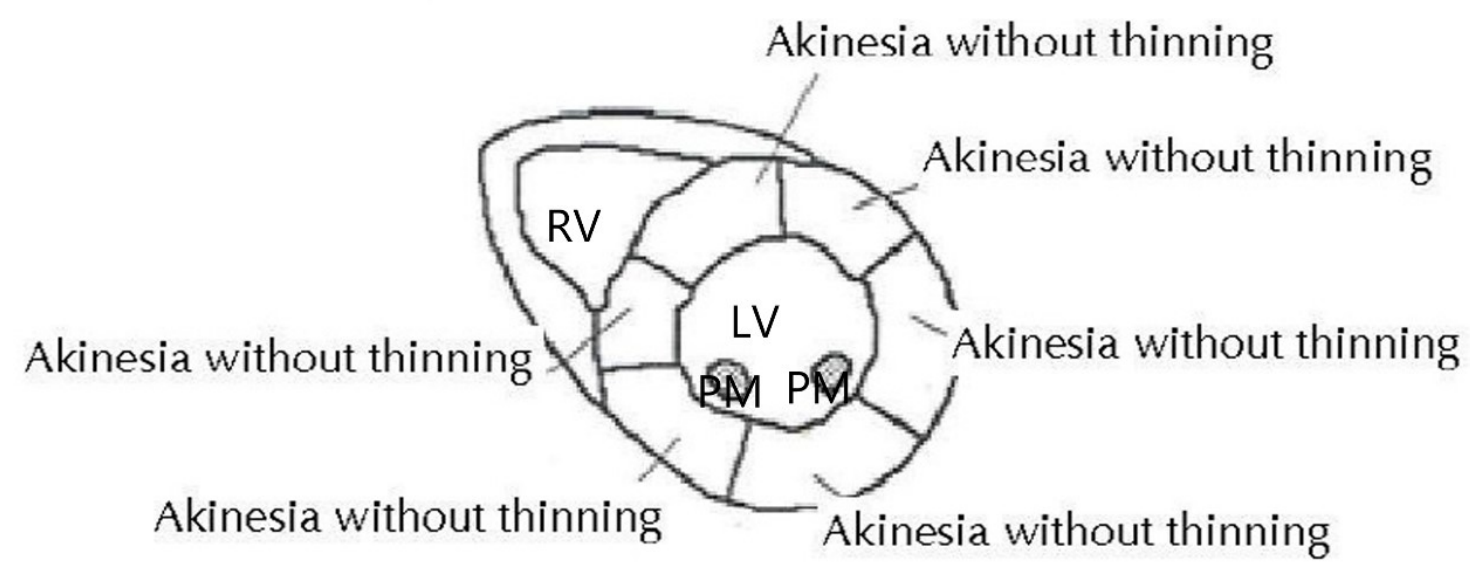

\section{Parasternal short axis - apex}

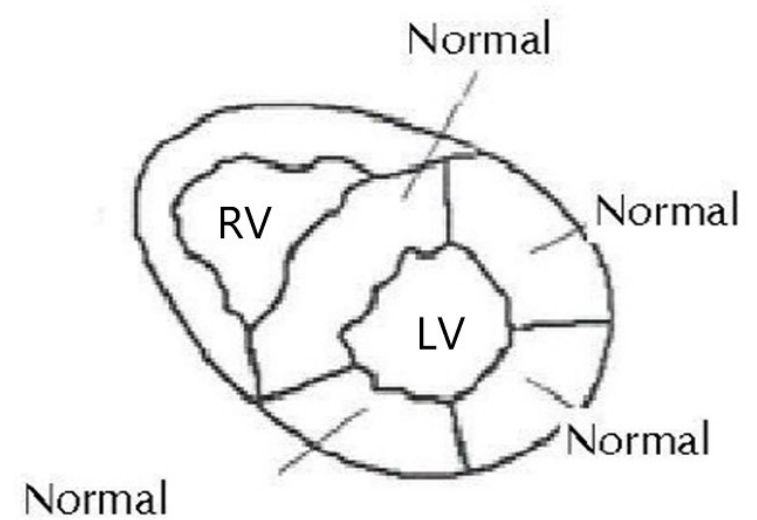

F I GURE 3. Analysis of regional wall motion seen on the patient's initial echocardiography. Left ventricle (LV), right ventricle (RV), left ventricular outflow tract (LVOT), mitral valve opening (MVO) papillary muscle (PM).

on the second day of hospitalization. Cardiac enzyme levels progressively decreased to the normal range on the third day of hospitalization, and follow-up chest radiography on the third day of hospitalization revealed resolved pulmonary edema (Fig. 2B). The patient was discharged without any symptoms on the fifth day of hospitalization. The results of the follow- 
up echocardiography performed at the outpatient department 2 weeks later were all normal.

\section{Discussion}

Epinephrine is a life-saving drug. However, one should always pay attention to the dosage and method of administration. There are various reports concerning epinephrine administration and its complications. In most of these case reports, complications arise from incorrect dosage or incorrect route of administration [1-4]. For comparison and clarity, a typical dose of epinephrine for the treatment of anaphylaxis is $0.3-0.5 \mathrm{mg}$ of 1 : 1000 epinephrine intramuscularly or $0.1 \mathrm{~mL}$ of 1 : 1000 solution in $10 \mathrm{~mL}$ of normal saline intravenously administered over 5-10 min [2]. Our patient accidentally self-administered 10 times the recommended dose for an anaphylactic patient in an instant. In a case reported by Khoueiry et al., the author describes the complications that arose after the patient was administered $1 \mathrm{mg}(1: 1000)$ of epinephrine intravenously as a treatment for anaphylaxis. The patient instantly complained of chest tightness, respiratory distress, and transient loss of consciousness. The patient's blood pressure dropped to $80 / 71 \mathrm{mmHg}$, and the laboratory results revealed cardiac enzymes above the normal range. Chest radiography revealed pulmonary congestion in both lung fields, and echocardiography revealed hypokinetic wall motion similar to our patient [4]. As in previously published case reports of complications associated with epinephrine injections, it is believed that catecholamine excess causes cardiotoxicity that eventually leads to SCMP [3-8]. Adverse cardiovascular effects can occur following epinephrine administration, ranging from inconsequential transient tachycardia to myocardial infarction. SCMP is also a potential iatrogenic complication of epinephrine administration. A recent systematic review found 41 cases of epinephrine-triggered SCMP [9]. The pathophysiology of SCMP is thought to be caused by the oxygenderived free radicals produced by the catecholamine when they react, which leads to membrane damage and myocyte death. Others report that platelet aggregation leads to vessel occlusions, calcium overload, or coronary vasoconstrictions [10]. The diagnosis of SCMP follows that of an acute coronary syndrome but without significant coronary stenosis or obstruction on coronary angiography. Our patient demonstrated a sudden drop in blood pressure, pulmonary edema, and elevated cardiac enzyme levels. The treatment of SCMP induced by epinephrine overdose is largely conservative with a symptomatic approach. The prognosis is favorable, as is in our case and many other reported cases $[1,6]$.

There are a few points to consider to avoid accidental injection. First, care must be taken to avoid medication errors. According to one case report, epinephrine stored in the same box as midazolam was accidentally injected during colonoscopy, causing serious complications [11]. As in the case reported here, if medications of similar shape are kept together and not checked before injection, there is a risk of incorrect medication administration.

Second, more rigorous supervision is mandatory to prevent medical staff from accessing drugs without a prescription. The problem herein was not that of an incorrect medication administered to a patient but a case where the medical staff used the drug without a prescription. Drug abuse can be detected through prescription drug monitoring programs [12]. However, healthcare professionals not only have high access to medications but can also be very difficult to monitor even if they use medications illegally. There was a paper published among physicians on misuse of prescribed medications [13]. A few years ago, in South Korea, cases of unprescribed use of propofol by medical staff were reported in the news, and measures to prevent medication abuse were discussed [14].

Furthermore, the higher the workload, the more safety issues can arise [15]. This applies to workplaces looking to handle the arduous workload without hiring enough staff. Our patient thought that she could continue working after an injection of an analgesic due to the lack of alternatives. For the safety of patients and medical staff, hospital administrators should consider improving the welfare of medical staff by employing sufficient staff.

\section{Conclusions}

The treatment of SCMP induced by epinephrine overdose is largely conservative with a symptomatic approach, and in most cases, has a good prognosis. Inappropriate administration of drugs in the wrong dosage and method can pose great risks to patients. Another important caveat to point out here is that the medical staff tried to administer an analgesic without a prescription. Stringent supervision and caution are required to prevent serious medication complications from accidental administration.

\section{AUTHOR CONTRIBUTIONS}

HK, JK examined the patient, diagnosed the case. HK wrote the first version. HY approved the final version of the paper and edited it. DK and HY read the literature and participated in writing. All authors contributed to editorial changes in the manuscript. All authors read and approved the final manuscript.

\section{ETHICS APPROVAL AND CONSENT TO PARTICIPATE}

This case report was approved by the Institutional Review Board of the Nowon Eulji Medical Center, Eulji University in Seoul, Korea (EMCS 2021-01-004).

\section{ACKNOWLEDGMENT}

We thanks, HyeYoung Han from Nowon Eulji Medical Center Library, for technical editing.

\section{CONFLICT OF INTEREST}

The authors declare that there is no conflict of interest regarding the publication of this article. 


\section{REFERENCES}

[1] Spina R, Song N, Kathir K, Muller DWM, Baron D. Takotsubo cardiomyopathy following unintentionally large subcutaneous adrenaline injection: a case report. European Heart Journal Case Reports. 2020; 2: yty043.

[2] Brian HR, Brian G. Allergy and anaphylaxis. In: Tintinalli J, Ma O, Yealy DM, et al., (eds.). Tintinalli's emergency medicine: a comprehensive study guide (pp. 68-73). 9th edn. New York: McGraw-Hill Education. 2020.

[3] Härle T, Kronberg K, Nef H, Möllmann H, Elsässer A. Inverted Takotsubo cardiomyopathy following accidental intravenous administration of epinephrine in a young woman. Clinical Research in Cardiology. 2011; 100: 471-473.

[4] Khoueiry G, Abi Rafeh N, Azab B, Markman E, Waked A, AbouRjaili $\mathrm{G}$, et al. Reverse Takotsubo cardiomyopathy in the setting of anaphylaxis treated with high-dose intravenous epinephrine. Journal of Emergency Medicine. 2013; 44: 96-99.

[5] André MC, Hammer J. Life-threatening accidental intravenous epinephrine overdose in a 12-year-old boy. Pediatric Emergency Care. 2019; 35: e110-e112.

[6] Taneli Väyrynen MJ, Luurila HO, Määttä TK, Kuisma MJ. Accidental intravenous administration of racemic adrenaline: two cases associated with adverse cardiac effects. European Journal of Emergency Medicine. 2005; 12: 225-229.

[7] Surineni K, Afzal MR, Barua R, Parashara D. Epinephrine-induced Takotsubo cardiomyopathy. Federal Practitioner. 2020; 33: 28-30.

[8] Paur H, Wright PT, Sikkel MB, Tranter MH, Mansfield C, O'Gara P, et al. High levels of circulating epinephrine trigger apical cardiodepression in a $\beta 2$-adrenergic receptor/Gi-dependent manner: a new model of Takotsubo cardiomyopathy. Circulation. 2012; 126: 697-706.
[9] Nazir S, Lohani S, Tachamo N, Ghimire S, Poudel DR, Donato A. Takotsubo cardiomyopathy associated with epinephrine use: a systematic review and meta-analysis. International Journal of Cardiology. 2017; 229 : 67-70.

[10] Jiang JP, Downing SE. Catecholamine cardiomyopathy: review and analysis of pathogenetic mechanisms. Yale Journal of Biology and Medicine. 1991; 63: 581-591.

[11] Gado A, Ebeid B, Axon A. Accidental IV administration of epinephrine instead of midazolam at colonoscopy. Alexandria Journal of Medicine. 2016; 52: 91-93.

[12] Griggs C, Weiner S, Feldman J. Prescription drug monitoring programs: examining limitations and future approaches. Western Journal of Emergency Medicine. 2015; 16: 67-70.

[13] Merlo LJ, Singhakant S, Cummings SM, Cottler LB. Reasons for misuse of prescription medication among physicians undergoing monitoring by a physician health program. Journal of Addiction Medicine. 2013; 7: 349353.

[14] Lee J. Propofol abuse in professionals. Journal of Korean Medical Science. 2013; 27: 1451-1452.

[15] Son YJ, Lee EK, Ko Y. Association of working hours and patient safety competencies with adverse nurse outcomes: a cross-sectional study. International Journal of Environmental Research and Public Health. 2019; 16: 4083 .

How to cite this article: Hyunseung Koh, Duk Ho Kim, Jinseong Kim, Heebum Yang. Accidental self-injection of intravenous epinephrine by healthcare personnel. Signa Vitae. 2021;17(4):212-216. doi:10.22514/sv.2021.033. 